\title{
VALOR Y DISTRIBUCIÓN: DE LA TEORÍA A LA NORMA ${ }^{1}$
}

\section{Mariano Fernández Enguita}

Universidad de Salamanca

E-mail: enguita@gugu.usal.es

\begin{abstract}
RESUMEN
Abordar la problemática de la desigualdad, o más exactamente de la justicia económica, requiere partir de un criterio distributivo contra el cual contrastar la distribución realmente existente. Locke propuso una teoría o norma de la apropiación original referida a la distribución de los recursos naturales, pero fue incapaz de resolver el problema de la justicia intergeneracional. Marx formuló una teoría del valor-trabajo incapaz de explicar por qué el empleo de la propia actividad como trabajo, en vez de su consumo como ocio, daría derecho a la apropiación del excedente, pero el uso de la riqueza como capital en vez de su consumo como renta, no. Rawls propone una teoría liberal de la justicia, el principio de diferencia, en la que cabe admitir las desigualdades con tal de que con ellas mejore la posición del peor situado. En este artículo se defiende la pertinencia de los tres problemas, que conciernen respectivamente a la apropiación de los recursos naturales (y, por extensión, de la riqueza heredada) y de los productos del trabajo y a la incentivación de las aportaciones extraordinarias. Pero se propone, también, una corrección de las tres: de la primera, sustituyendo la apropiación original por las dotaciones iniciales para dar cabida a la igualdad entre generaciones; de la segunda, recurriendo a una norma del valor trabajo ampliada que incluya la retribución de la abstinencia, es decir, del capital; de la tercera, en fin, sustituyendo su aceptación sin más por la idea de partir la diferencia, es decir, de reducir la recompensa por las aportaciones extraordinarias al incentivo necesario para las mismas.
\end{abstract}

${ }^{1}$ Este trabajo ha sido posible gracias al patrocinio de la Comisión Interministerial de Ciencia y Tecnología, proyecto PB94-1382. 
La economía en particular y la ciencia social en general han buscado reiteradamente una teoría del valor por tres motivos básicos: primero, para explicar por qué unas cosas y acciones son bienes económicos y otras no; segundo, para discutir la justicia de las pautas de distribución existentes; tercero, para encontrar un mecanismo subyacente al visible desorden del sistema de precios. La mezcla de estos tres problemas, que en realidad requieren tres teorías distintas - y, en algunos aspectos, distantes_- ha sido la principal causa de las dificultades con que ha tropezado toda tentativa de formular una teoría capaz de explicarlos de manera unitaria. El marxismo fue el intento más ambicioso a este respecto, un esfuerzo colosal por embutir y articular dentro de una única teoría tres planos discretos de la realidad, reduciéndolos a una dimensión común, y, por ello mismo, el mejor ejemplo de confusión.

En este artículo nos ocuparemos exclusivamente del segundo problema mencionado. En los apartados primero y segundo abordaremos la formulación de lo que ya no podremos llamar una teoría del valor, sino una norma de valor (¿no es eso, necesariamente, la norma, lo que corresponde a los valores?) o, lo que es lo mismo, una norma de atribución, para dos tipos de bienes económicos: los productos del trabajo o, más en general, de los factores (tierra, trabajo y capital, ¡cómo no!), y los recursos naturales, respectivamente. En el apartado tercero consideraremos el problema de los incentivos a la producción, un espacio de las normas de atribución que consideramos parte del ámbito de la legitimidad pero no del de la justicia. El cuarto y último recapitulará las diferencias entre los tres modos legítimos de acceso a los bienes: recolección de los recursos naturales, retribución por la contribución de los factores y recompensa por las aportaciones extraordinarias.

El presente artículo es parte de una empresa más amplia, el análisis de la desigualdad, parte de la cual es el problema de la justicia de las transacciones económicas o, dicho de modo más expresivo, la explotación. El interés concreto de la cuestión del "valor» reside en que, sin resolverla o sin, al menos, mostrar que es soluble, no es posible plantear siquiera la problemática de la equidad económica o de la justicia distributiva. Para que lo sea es necesario mostrar que es posible una norma del valor en la que éste sea distinto del precio, pues de otro modo no habría caso para la igualdad o la equidad, ya que toda transacción voluntaria sería, por definición, justa, equitativa, no explotadora; en el extremo, bastaría con mostrar la posibilidad de tal norma de valor, sin entrar en su forma concreta, pero resultaría algo forzado pretender que se admitiera aquélla sin discutir siquiera algún ejemplo de ésta. Por eso intentaremos abordarlo con dos objetivos: primero, sugerir una norma de atribución sensata y justa en su forma concreta; segundo, mostrar con ello que es posible formular alguna norma, aunque no tenga que ser necesariamente ésta.

No obstante, la teoría normativa del valor que a continuación se propone no sólo es simplemente una más entre las posibles (se podría atribuir el valor, es decir, el derecho sobre los bienes, en función de la interpretación de los astros, del resto que arrojara dividir la fecha de nacimiento por la estatura o de los 
resultados de una tómbola a celebrar cada mañana, por ejemplo), sino también, o más bien, y esto es sin duda más importante, una más entre las razonables $^{2}$ (entre las varias que personas sensatas e informadas estarían dispuestas a considerar). Por supuesto, una más no quiere decir una cualquiera, pues no tendría sentido perder en tal el tiempo del lector y del autor. Quiere decir que, una vez que partimos de que la justicia de la distribución (el valor entendido como tal) es un problema normativo, sería absurdo pretender que hay una teoría o norma perfecta frente a todas las demás equivocadas y es preciso admitir que, aunque consideremos alguna como la mejor posible - en circunstancias dadas-, puede haber y seguramente habrá otras casi tan buenas o, al menos, dignas de ser tenidas en cuenta.

\section{UNA TEORÍA AMPLIADA DEL «VALOR-TRABAJO»}

En la economía de subsistencia, el hogar produce todo o la mayor parte de lo que consume y consume todo o la mayor parte de lo que produce. Estas circunstancias dictan los términos en que se plantea (o en que no se plantea) el problema de la distribución. Por un lado, la distribución interna al hogar sigue las pautas de las relaciones de fuerza y parentesco, probablemente priorizando la supervivencia de los más fuertes, lo que es una forma indirecta de priorizar la supervivencia del grupo sobre los individuos. Por otro, el problema de la distribución externa se centra sobre todo en el acceso a los recursos naturales. En el caso de los cazadores recolectores, el uso extensivo del territorio convierte esto en cuestión de relaciones entre clanes o grupos plenamente autosuficientes y, por tanto, de movilidad y, llegado el caso, de guerra. En el caso de los pueblos agricultores, con un uso mucho más intensivo de la tierra, el problema de la distribución se desdobla: por un lado, el acceso de cada hogar a una cantidad suficiente de la misma; por otro, la distribución de las cargas colectivas. En uno como en otro, la producción y la distribución se presentan siempre soldadas a las relaciones de parentesco o a relaciones más amplias de dependencia personal.

En las economías de división del trabajo desarrollada se separan producción y consumo y, por ello, trabajo y consumo. El trabajo aparece como una actividad discernible espacial, temporal y funcionalmente de cualquier otra; el producto, que ya no se consume in situ ni por el productor, se presenta también como un conjunto independiente de bienes separados o de servicios en los que se distingue con claridad a quien los presta de quien los recibe. Con la producción cooperativa se deslindan también el trabajo y su producto, en tér-

2 Pretendo usar el adjetivo razonables — distinto de racionales - en el mismo sentido en que lo hace Rawls (1993: 67, 74, 83, 165 et passim) cuando habla de "pluralismo razonable», "doctrinas comprehensivas razonables», etc. En realidad es la acepción común del término, como cuando se afirma de algo con lo que no se está de acuerdo que, no obstante, se puede discutir. 
minos técnicos, y el trabajador y los medios de producción. En estas circunstancias es cuando necesariamente estallan entre los participantes el problema de su participación en la producción y en la apropiación y el problema de los términos del intercambio o la asignación. En otras palabras, el problema de la equivalencia entre los factores y el producto, en la producción, o entre lo que se da y lo que se recibe, en la circulación. Por otra parte, puesto que el aprovechamiento de los recursos naturales ya no tiene lugar por el grupo o como parte del grupo, se añade el problema de su apropiación, originaria o derivada.

Una parte muy importante de la riqueza, los llamados bienes reproducibles, se produce mediante el trabajo y sólo con la mediación del trabajo (aunque no sólo con trabajo directo, sino también con recursos naturales y trabajo acumulado). Con el paso de la agricultura a la industria y de ésta a los servicios se hace más visible el papel del trabajo en la producción. De hecho, toda la tradición de pensamiento liberal e individualista arranca del postulado de que la libertad humana da al hombre un derecho sobre los productos de su trabajo. Fue principalmente Locke quien basó la legitimidad de la propiedad y de la apropiación originaria de la tierra en el trabajo, afirmando sin equívocos que el trabajo y el producto del trabajo son propiedad del trabajador $^{3}$ (si bien, siendo el trabajo alienable, los productos del trabajo alienado pertenecen a quien lo ha adquirido: he ahí la justificación del capitalismo). Subidos a su estela, los economistas clásicos buscaron en el trabajo la causa última de los precios, una medida «objetiva» del valor y puede decirse que, implícitamente, una norma de distribución. Podía tratarse del trabajo socialmente necesario para la producción de la mercancía, según Marx ${ }^{4}$, incorporado de hecho, según Ricardo5, o susceptible de ser adquirido con su venta, según $S \mathrm{Smith}^{6}$, pero trabajo al fin y al cabo. Sin embargo, la diferencia crucial entre Smith, de un lado, y Ricardo y Marx, de otro, es que aquél fue plenamente consciente de que las mercancías sólo se cambian a precios correspondientes a sus valores-trabajo cuando no hay apropiación (privada y diferencial) de la tierra ni acumulación (privada y desigual) de capital ${ }^{7}$.

${ }^{3}$ «[S]iempre que alguien saca alguna cosa del estado en que la Naturaleza la produjo y la dejó, ha puesto en esa cosa algo de su esfuerzo, le ha agregado algo que es suyo; y, por ello, la ha convertido en propiedad suya. [...] Siendo, pues, el trabajo o esfuerzo propiedad indiscutible del trabajador, nadie puede tener derecho a lo que resulta después de esa agregación [...]» (Locke, 1690: $\$ 26)$.

${ }^{4}$ «Es sólo la cantidad de trabajo socialmente necesario, pues, o el tiempo de trabajo socialmente necesario para la producción de un valor de uso, lo que determina su magnitud de valor» (Marx, 1867: I/1, 48).

5 «El valor de un bien económico, o sea, la cantidad de cualquier otro bien por la cual podrá cambiarse, depende de la cantidad relativa de trabajo necesaria para producirlo» (Ricardo, 1817: 19).

${ }^{6}$ «El valor de cualquier mercancía, por tanto, para la persona que la posee y que no pretende usarla ni consumirla por sí misma sino cambiarla por otras mercancías, es igual a la cantidad de trabajo que le permite comprar o dirigir. El trabajo, por tanto, es la medida real del valor de cambio de todas las mercancías» (Smith, 1776: 133).

7 «En ese rudo estadio de la naturaleza que precede a la acumulación de capital y la apropiación de la tierra [...]» (Smith, 1776: 150). 
El reconocimiento del trabajo como fuente de valor no implica necesariamente el postulado de que quien trabaja tiene derecho al producto de su trabajo, sea éste individual o cooperativo, pero nos acerca a él. Smith, sencillamente, no hizo problema de ello. Dio por sentado que sólo el trabajo daba o añadía valor a los objetos, pero también que se dividía entre salarios y beneficios, dando lugar a lo que se ha dado en llamar la teoría del beneficio como deducción del producto del trabajo. Quizá precisamente porque Smith buscaba en el valor, directamente, el precio real frente al precio nominal sujeto a las variaciones en el valor de cambio del dinero, se viera obligado antes a abandonar esa vía muerta. Ricardo heredó el problema, pero lo formuló en términos más generales como el problema global de la distribución del producto, que concierne tanto a los términos cuantitativos de la distribución (los precios) como a su misma naturaleza cualitativa, es decir, a qué es lo que hace que en ella intervengan no solamente el trabajo, sino también el capital y la tierra ${ }^{8}$. Marx, por su parte, quiso fundir la visión normativa del problema, o quién debe apropiarse del producto, con su análisis positivo, o cuál es la fuente del valor, pregunta que puede considerarse como el trasunto metafísico de la relación entre valor y precios, o de la lógica inherente de los precios: la síntesis, el socialismo cientifico.

En todo caso, para los bienes y servicios en cuya producción - o en la producción de cuyos medios de producción o materiales de trabajo- interviene de forma significativa el trabajo, tiene sentido una norma de atribución según el trabajo aportado. Si sólo el trabajo, como dice Locke, saca a los recursos naturales del estado de naturaleza en que pertenecen a todos y a ninguno a la vez, porque sólo el trabajo pone en ellos algo propio de una persona y no de todas, distintos bienes que hayan sido objeto del trabajo de distintas personas deberán ser objeto de apropiación por cada una de ellas y los bienes que hayan sido objeto de trabajo conjunto deberán ser objeto de apropiación conjunta. Entendida, pues, como teoría normativa, o simplemente como norma de atribución, la teoría del valor trabajo, en este sentido restrictivo, parece una buena teoría - es decir, una buena norma- en lo que concierne a los bienes económicos reproducibles.

Hay una serie de pormenores en los que no necesitamos entrar, porque son enteramente secundarios. La aportación en trabajo podría medirse, por ejemplo, en tiempo, en kilogramos-fuerza, en calorías, en quanta de materia-energía...; para todos por igual o en función de la fuerza física, las condiciones de salud, etcétera. Supongamos simplemente que, dada la imperfección de nuestros instrumentos de medida y dados los altos costes que supondría intentar utilizar otro tipo de información, nos conformamos con ese primitivo instrumento llamado reloj para medir el trabajo por el tiempo de trabajo, suponiendo una intensidad y una habilidad medias. Las variaciones en intensidad y habilidad para la pro-

8 «El problema fundamental de la Economía Política consiste en determinar las leyes que regulan esta distribución» (Ricardo, 1817: 15). 
ducción de mercancías normalizadas serán convenientemente registradas por el mercado. Supondremos, pues, que el trabajo es el tiempo de trabajo.

Aunque la naturaleza es de todos, el trabajo sólo puede ser de quien lo realiza. La explotación del trabajo, pues, sólo puede ser una acción entre personas adultas y capaces. Un niño al que se pone a trabajar puede ser explotado, pero un niño que no trabaja no por ello explota a sus padres. También quedan excluidos de esta posibilidad los adultos no capacitados para trabajar: la sociedad se obliga a sostener sus vidas, y ello a un nivel digno y suficiente, porque la naturaleza o el azar han sido injustos con ellos (discapacitados) o porque ya han hecho su contribución (ancianos). Si los recursos procedieran todos de la naturaleza, como el maná, sin trabajo alguno, los niños y los discapacitados sólo tendrían que abrir la boca y tomarlos, al igual que los demás, sin aportar nada. Una vez que proceden en mayor o menor parte del trabajo, pero que la naturaleza no les ha dotado - todavía o con carácter definitivo- para ello, la sociedad, sea a través de la familia, del Estado, de otras instituciones intermedias o de cualquier combinación de ellas, asume la carga correspondiente. Desde este punto de vista son, podría decirse, bienes de lujo, y la parte del producto social que va a ellos no puede considerarse perdida sino consumida, y felizmente (o al menos moralmente) consumida, por quienes la aportan. Esto significa que, en principio y como tales, los hijos no explotan a los padres y los discapacitados no explotan a los capaces de trabajar.

Hemos mencionado sólo la duración y la intensidad del trabajo, pero debemos añadir ahora la cualificación, entendiendo por tal la cualificación adquirida (es decir, la cualificación del trabajo — productivo- por medio del trabajo - aprendizaje-). Esto significa negar que nadie/alguien pueda tener mayor o mejor derecho que otros por sus cualidades especiales innatas, un punto que sin duda será controvertido. Cuando menos, no debería sorprender si no lo hizo antes la afirmación de que los niños y los incapaces tienen los mismos derechos, tanto sobre los productos de la naturaleza como sobre los productos del trabajo, que los adultos capaces, pues esta nueva afirmación es el reverso de la anterior: si la suerte en lo que concierne a los dones personales recibidos de la naturaleza no puede disminuir los derechos, tampoco debe poder aumentarlos.

Un libertario (lo que ahora se llama libertarios) pondrá de inmediato el grito en el cielo: ¿acaso no somos dueños de nosotros mismos y, por tanto, de nuestras facultades naturales y, por consiguiente, de todo lo que ellas nos permitan conseguir por medios legítimos?? El problema esencial es que nuestras capacidades naturales no tienen por qué otorgarnos los mismos derechos en la

9 «1. Las personas tienen derecho a sus capacidades naturales. 2. Si las personas tienen derecho a algo, también lo tienen a lo que quiera que derive de ello (vía tipos especificados de procesos). 3. Las posesiones de las personas derivan de sus capacidades naturales. Por consiguiente, 4. Las personas tienen derecho a sus posesiones. 5. Si las personas tienen derecho a algo, deben tenerlo (y esto está por encima de cualquier presunción de igualdad que pudiera haber sobre las posesiones)»(Nozick, 1974: 225-226). 
naturaleza y en la sociedad, pero esta discusión queda para otro momento y lugar. En general, las que llamamos cualidades naturales suelen tener mucho menos de naturales y mucho más de adquiridas (por mecanismos mono u oligopolistas) de lo que se supone: por ejemplo, la inteligencia, la iniciativa, etc. Incluso las que más obviamente parecen naturales pueden ser en gran medida de origen natural, pero sólo se convierten en cualidades en un contexto social. Las cualidades cantoras de Caruso o las cualidades pintoras de Picasso no les habrían servido de mucho en estado de naturaleza, es decir, sin una cultura que las apreciara, un mercado que las pagara y un estado que las protegiera. No obstante, baste decir aquí, por un lado, que la mayor parte de las cualidades naturales no pasan de potencialidades sin un adecuado cultivo, lo que las convierte también —al menos en parte- en cualificaciones; por otro, que queda abierto el problema de cómo lograr que la sociedad saque provecho de estas cualidades excepcionales, pero esto pertenece más bien al ámbito de los incentivos que al de los derechos, lo que es otra forma de decir que es más un problema de eficacia que de justicia.

Más importante es la cuestión de los medios de producción. El marxismo, principal valedor de la teoría del valor-trabajo, estableció una diferencia tajante entre trabajo vivo y trabajo muerto, a la que correspondería la dicotomía entre capital variable y capital constante. Llama poderosamente la atención la eficacia con la que Marx logró convencer a su público, en un estilo propio del mejor discípulo de Hegel, de que trabajo y capital eran a la vez lo mismo y lo opuesto - la unidad de los contrarios - El capital, por un lado, es trabajo acumulado, cristalizado, objetivado; el trabajo, por otro, no es sino un momento en el ciclo del capital, el capital variable. Los adjetivos, nada inocentes, con los que Marx los distinguió encerraban ya en sí toda una teoría: trabajo vivo frente a trabajo muerto: ¿cómo podría tener derechos el trabajo muerto y cómo podría dejar de tenerlos el vivo? Capital variable, que crea por sí solo el valor, todo nuevo valor, y capital constante, cuyo valor simplemente es transferido sin aumento ni disminución al producto. Pero ¿en qué se funda la idea de que el trabajo vivo crea valor? Por un lado, en el artilugio de utilizarlo como numerario, es decir, en el espejismo producido por el hecho de que el valor de cualquier mercancía puede expresarse en trabajo, lo mismo que podría expresarse en cualquier otra mercancía, por lo que debemos dejar de lado este motivo. Por otro, en lo que el trabajo tiene de distintivamente humano, o sea, en que es la aportación específica del hombre al producto - el resto lo aporta la naturaleza-, y en la relación instrumental que le une al producto, es decir, en que se trabaja para producir y obtener ese producto.

Marx pretendía que el trabajo crea efectivamente algo que podría llamarse valor, una especie de cristalización de la relación social, de la equivalencia profunda de todo trabajo humano. Es fácil comprender que tal pretensión es metafísica y que la teoría del valor-trabajo sólo puede mantenerse como norma de atribución del producto según el trabajo aportado. Ahora bien, si podemos y debemos atribuir valor (o sea, una parte del producto) al trabajo actuante, ¿por qué 
no podemos y debemos atribuírselo también al trabajo acumulado? Para afrontar esta pregunta con la cabeza fría, tal vez sea útil despejar de ésta la imagen típica del capitalista con puro y chistera y sustituirla, simplemente, por la de un trabajador que convierte una parte del producto que se ha apropiado en medios de producción y aporta éstos al ciclo siguiente: en definitiva, un pequeño inversor. Así como el trabajador renuncia a ver pasar su tiempo en la inactividad y a consumirlo como ocio, el pequeño inversor renuncia a guardar su producto inactivo y a consumirlo como un bien final. Sus derechos sobre el producto futuro proceden de que los dos aportan trabajo, vivo el uno y objetivado el otro, y pueden compatibilizarse y compararse fácilmente porque sus aportaciones son plenamente conmensurables, ya que ambas pueden medirse en tiempo de trabajo ${ }^{10}$.

\section{CUADRO 1}

\section{Trabajo y medios de producción}

\begin{tabular}{|c|c|c|}
\hline & Trabajo humano directo & Medios de producción producidos \\
\hline En otros términos & $\begin{array}{l}\text { Trabajo presente, directo, } \\
\text { inmediato, actual }\end{array}$ & $\begin{array}{l}\text { Trabajo pretérito, indirecto, } \\
\text { mediato, acumulado }\end{array}$ \\
\hline \multicolumn{3}{|c|}{ En la teoría del valor-trabajo de Marx } \\
\hline Se considera como & Trabajo vivo & Trabajo muerto \\
\hline \multirow{2}{*}{$\begin{array}{l}\text { Relación con el valor del } \\
\text { producto }\end{array}$} & Se transfiere el valor del factor, & Se transfiere el valor del factor, \\
\hline & crea valor nuevo & no crea valor nuevo \\
\hline Retribución por & $\begin{array}{l}\text { Salario, tendente hacia el pre- } \\
\text { cio de la fuerza de trabajo }\end{array}$ & $\begin{array}{l}\text { Beneficio, extraído del traba- } \\
\text { jo no retribuido o plusvalor }\end{array}$ \\
\hline \multicolumn{3}{|c|}{ En la norma de atribución aqui postulada } \\
\hline Su contribución se mide en & $\begin{array}{l}\text { Tiempo de trabajo realizado } \\
\text { (presente) }\end{array}$ & $\begin{array}{l}\text { Tiempo de trabajo acumula- } \\
\text { do (pretérito) }\end{array}$ \\
\hline Se retribuye en calidad de & Esfuerzo & Privación \\
\hline Porque es alternativo a & Inactividad y ocio & Ahorro y consumo \\
\hline Y se remunera como & Salario & Alquiler o interés \\
\hline Su precio real depende de & $\begin{array}{l}\text { Escasez, si es por cuenta pro- } \\
\text { pia } \\
\text { Id. más relación de fuerzas, si } \\
\text { interviene en producción } \\
\text { cooperativa }\end{array}$ & $\begin{array}{l}\text { Escasez, si es alquilado o } \\
\text { prestado } \\
\text { Id. más relación de fuerzas, si } \\
\text { interviene en producción } \\
\text { cooperativa }\end{array}$ \\
\hline
\end{tabular}

${ }_{10}$ «En verdad, la división primaria de la riqueza a distribuir es dual, no tripartita. El capital no es más que una forma de trabajo, y su distinción del trabajo no es en realidad más que una subdivisión, tal como lo sería la división del trabajo en cualificado y no cualificado" (George, 1879: cap. X). 
De hecho, la pretensión de Marx de que el valor de los medios de producción simplemente se transfiere sin incremento alguno al producto resulta insostenible. Por un lado, porque excluye que quien contribuye con trabajo vivo explote a quien contribuye con trabajo acumulado, cosa que puede resultar incluso atractiva frente al estereotipado capitalista de la chistera pero que sería difícil de justificar frente al trabajador ahorrativo, el suscriptor de un fondo de pensiones, el pequeño inversor, etc. Por otro, porque se hace complicado comprender cómo el valor de los medios de producción no puede sino transferirse inalterado al producto cuando el valor de éste supera al valor inicial total del capital pero deja de hacerlo cuando queda por debajo; dicho de otro modo, cómo podría sufrir decrementos algo que no puede conocer incrementos. Por una paradoja, en la realidad económica, tan distinta a veces de las peticiones de principio de la ortodoxia, lo que se mantiene por más tiempo inalterado, cualquiera que sea la suerte del producto en el mercado, es el salario del trabajador, es decir, la parte fantasmagóricamente variable del capital. $\mathrm{Ni}$ que decirse tiene que esta petición de principio marxiana tiene su correlato en la pretensión simétrica del capital según la cual el valor del trabajo, o sea, la retribución que debe obtener el trabajador, no es otra que su salario, sin ninguna posibilidad de participación en los beneficios... con la diferencia de que esta pretensión se apoya además en la fuerza y resulta, por ello, normalmente efectiva.

Salta a la vista una diferencia entre el trabajo vivo y el trabajo acumulado: que las desigualdades interindividuales en su posesión son limitadas en el caso del primero y potencialmente más amplias, incluso ilimitadas, en el del segundo. Otra diferencia esencial y pertinente a nuestro objeto, en realidad otra faceta de lo mismo, reside en su distinto grado de separabilidad, alienabilidad, renovabilidad, etc. Todo ello puede bastar para poner en una sistemática posición de ventaja a quienes contribuyen a la producción con trabajo acumulado frente a quienes lo hacen con trabajo inmediato, pero las ventajas que de aquí se siguen suelen proceder más bien de la diferencia de escala, o al menos tenerla como requisito, lo cual modifica por entero el escenario del problema. El problema surge cuando el inversor, convertido en capitalista, se enfrenta al trabajador y lo hace provisto de una masa ingente e imprescindible de medios de producción que le permite tornar decisivamente a su favor los términos de la apropiación del producto, pero para alcanzar la masa crítica de medios de producción que suponga una ventaja decisiva frente a quien no los posee ha de mediar algo más que el ahorro, concretamente la explotación, la herencia o, lo que es más probable, ambas, y no sólo a favor de una persona o un número reducido de personas, sino a favor de una clase social. Una de las grandes insuficiencias del marxismo ha sido, precisamente, criticar el capitalismo en unos términos (la negación del derecho del propietario de los medios de producción sobre el valor ampliado del producto) sin duda atractivos para una clase obrera desposeída como la de la revolución industrial, pero inaceptables por completo para la pequeña burguesía de todos los tiempos, incluido el pequeño campesi- 
nado propietario, y para una masa de trabajadores crecientemente vinculados o dispuestos a vincularse a la propiedad de los medios de producción a través de participaciones en los beneficios, fondos de pensiones o de inversión, pequeñas participaciones accionariales individuales, etc. Además de inaceptables, por cierto, para el sentido común.

Podemos considerar esto como una versión ampliada de la teoría marxista del valor-trabajo, pero me parece más adecuado presentarlo, simplemente, como una norma universal de atribución del producto en proporción al trabajo aportado, norma que Marx y el marxismo teórico quisieron arbitrariamente limitar al caso del trabajo vivo y que el capitalismo práctico ha limitado de hecho, con no menos arbitrariedad pero con mucha mayor efectividad, al caso del trabajo acumulado. El cuadro 1 esquematiza las diferencias entre la teoría del valor de Marx y la norma de valor aquí sugerida.

\section{DE LA APROPIACIÓN ORIGINAL A LA DOTACIÓN INICIAL}

Pero otra parte importante de la riqueza son recursos naturales que no requieren trabajo, o sólo lo hacen en cantidades insignificantes ${ }^{11}$. En tales circunstancias, es irrelevante el trabajo y puede resultar más plausible una teoría de la justicia distributiva que considere sujetos de iguales derechos a todos los seres humanos, todos los adultos, todas las familias, etc. Antes de la industrialización, en la economía natural o predominantemente natural, las normas de la distribución se situaban por lo común más cerca de esta segunda variante: así, por ejemplo, la redistribución periódica de la tierra en diversas culturas agrarias, los derechos medievales compartidos sobre la misma e incluso las revueltas campesinas tardías por su redistribución; es sólo a partir de la revolución industrial, cuando la riqueza parece manifiestamente derivar de la actividad humana que domina a la naturaleza, de la intervención del trabajo y de los medios de producción producidos —o sea, del capital en sentido clásico-, que las teorías de la distribución giran de modo prioritario en torno al trabajo y, las normas efectivas, en torno al capital. Por más que el desarrollo sucesivo de la agricultura, la industria y los servicios haya ido haciendo aumentar el peso relativo del trabajo vivo y del trabajo acumulado, no deja de ser cierto que seguimos utilizando recursos naturales. El reconocimiento de la naturaleza como fuente de valor implica que cada cual tiene derecho a apropiarse de lo que necesite y desee de ella, sin otro límite que los derechos de los demás, y la forma más obvia de aplicar este principio es reconocer a cada cual el derecho a una parte igual de los recursos naturales. Puede decirse que la distribución per capita de los recursos naturales es la que cuadra mejor a una economía de sub-

11 «La distinción real y natural es entre las cosas que son producto del trabajo y las cosas que son ofrecimientos gratuitos de la naturaleza; o, por decirlo en los términos de la Economía Política, entre la riqueza y la tierra" (George, 1879: cap. XX). 
sistencia, mientras que la distribución pro labore de los productos del trabajo lo hace a una economía de producción para el cambio.

El derecho a los recursos naturales puede regularse de diversas formas: como derecho de primer ocupante sin límite alguno, como derecho a apropiarse de los recursos naturales con el límite del propio trabajo y/o las propias necesidades o como derecho limitado por los derechos iguales de los demás. Si excluimos la primera posibilidad, la segunda y la tercera podrían expresarse mejor como apropiación proporcional (según el trabajo o las necesidades) y apropiación per capita, en partes iguales por el mero hecho de existir. De las dos opciones parece más razonable la apropiación igualitaria, per capita, por varios motivos. En primer lugar, si se trata de la apropiación de los recursos naturales como tales, es decir, sin su transformación por el trabajo, resulta difícil justificar la pertinencia de éste. En segundo, a los recursos naturales cuadran mejor los derechos naturales, es decir, los derechos ontológicamente anteriores al trabajo. En tercero, la apropiación per capita no excluye a los incapacitados para trabajar, que se distinguen de los demás hombres por esa incapacidad pero son iguales a ellos en su condición humana. En cuarto, la apropiación per capita es necesariamente más igualitaria en sus resultados que cualquier forma de apropiación proporcional. En quinto, resulta más acorde con la tradición liberal sobre la apropiación originaria.

La forma primera de apropiación de la naturaleza fue la apropiación en común, bien fuese para su uso igualmente en común, como en el caso de la caza y recolección, bien para su uso individual respetando el acceso y las necesidades de los otros miembros del grupo, como en el caso del aprovechamiento de las tierras comunales para el pastoreo, la recogida de madera, etc. Una vez que la agricultura elevó espectacularmente la productividad de la tierra, lo que significa que alteró radicalmente el peso relativo del proceso de la naturaleza y el trabajo del hombre del lado de éste, el problema tenía que plantearse necesariamente en términos de apropiación particular. Una solución posible era y fue la apropiación por parte de los hogares familiares, pero con reversión de la tierra a la comunidad al perecer o disolverse el hogar, como era el caso del mir ruso, de la comunidad aldeana en algunas formas de despotismo oriental o de algunas culturas agrícolas africanas. Otra, la apropiación definitiva por los hogares, incluida la transmisión intergeneracional a través de la herencia, con la concentración del poder de disposición en la figura del patriarca o cabeza de familia y con su correlato de obligaciones mutuas entre los miembros de la familia y regulación de la sucesión. Finalmente, la apropiación estrictamente individual, libre o sustancialmente libre de los límites directos impuestos por los vínculos familiares, que se distingue de la anterior, sobre todo, por la alienabilidad plena de la propiedad en contraposición a las limitaciones y obligaciones sucesorias.

Pero, una vez que se pasa de la apropiación en común (con disfrute en común o particular) a la apropiación particular, sea por hogares o personas, se plantea el problema de la justicia de la misma, es decir, el problema de los 
derechos individuales sobre los recursos naturales. Si se admite, como generalmente se admite, que las transacciones con los recursos naturales son libres, y nada habrá que objetar a ellas si están exentas de explotación, el problema se reduce entonces a la apropiación primera u original de recursos naturales que nadie posee, res nullius. Tanto si los sujetos de la apropiación son las personas como si son los hogares o cualesquiera otros grupos particulares, la afirmación de este derecho a lo que nadie posee suele ir acompañada de lo que se llama la cláusula lockeana. Según Locke (1690: $\$ 32)$, todo hombre puede apropiarse libremente de la tierra mientras quede todavía tanta y tan buena para los demás ${ }^{12}$. Pero la cuestión es a quién y cuándo se aplica la cláusula.

En primer lugar, nos desprenderemos del resto de Locke para quedarnos sólo con la mencionada cláusula. Para el pensador liberal, los límites de la apropiación original eran tres: la mencionada cláusula, lo que un hombre puede trabajar y sus necesidades ${ }^{13}$. Como ha argumentado muy convincentemente Macpherson (1962), su obra no es tanto la defensa de estos límites como una colección de silogismos que conducen a la mejor forma de olvidarlos, pero aquí podemos ser más expeditivos. De hecho, no hay razón alguna para que el trabajo y las necesidades sean límites de la apropiación originaria. Si la naturaleza fuera el maná, o en la medida en que es el maná (en que puede consumirse sin trabajo), y si fuera superabundante, resulta difícil ver la razón por la que su apropiación debería estar sujeta a esos límites. El límite razonable no son las propias necesidades, sino las necesidades de los demás - $\mathrm{y}$, puesto que no hay manera consensuable de medir las distintas necesidades subjetivas, el límite son simplemente los demás, lo cual conduce al reparto igualitario-. En cuanto al trabajo, ¿por qué no podría cada cual decidir con su propia parcela si se conforma con los frutos que pueda extraer de ella mediante la cazarecolección, si recurre al trabajo agrícola o si se lanza a la empresa industrial?

Lo fundamental, lo que convierte la naturaleza en un bien económico, no libre, es la escasez, y, una vez que hay escasez, es cuando cobra sentido la cláusula lockeana. Pero ¿̇cuándo y para quién? Locke parte del supuesto de la existencia de bienes libres, situación que puede presumirse en los orígenes de cualquier sociedad (ya que sin sociedad no hay derecho), no importa el momento en el tiempo, o en los procesos de conquista y colonización. Locke se encontró así con la feliz circunstancia de que, si bien las tierras inglesas y europeas resultaban ya en su tiempo más bien escasas y desigualmente repartidas, podían encontrarse de nuevo en abundancia en las colonias (ignorando, por supuesto, la apropiación original y las transacciones legítimas entre sus anteriores habitantes $)^{14}$. Aun así, y

12 «Ningún daño se causaba a los demás hombres con la apropiación, mediante su mejora y cultivo, de una parcela de tierra, puesto que quedaba disponible todavía tierra suficiente y tan buena como aquélla, en cantidad superior a la que podían utilizar los que aún no la tenían» (Locke, 1690: $\$ 32$ ).

13 «La medida de la propiedad la señaló bien la Naturaleza limitándola a lo que alcanzan el trabajo de un hombre y las necesidades de la vida” (Locke, 1690: $\$ 35$ ).

${ }_{14} \mathrm{O}$, subsidiariamente, ignorando su trabajo y sus necesidades como no civilizados, con lo cual recobrarían vigor las otras dos cláusulas. 
salvo que Locke imaginase a la humanidad conquistando otros planetas, el problema quedaría simplemente pospuesto hasta la total apropiación de las colonias, y resulta difícil saber cómo participaron en la apropiación original de la metrópoli las generaciones intermedias entre los primeros llegados y el descubrimiento de las futuras colonias. En otras palabras, tarde o temprano ha de plantearse el problema de si la cláusula lockeana se aplica sólo en un momento dado, cada vez que hay tierras disponibles por causas exógenas o a través de las generaciones y para todas ellas.

Tanto en el primer caso como en el segundo, los que llegan tarde no pueden participar ya en la apropiación de los recursos naturales, pero entonces no se ve por qué deberían respetar la que tuvo lugar sin contar con ellos. Este callejón sólo tiene dos salidas: una es considerar que los sujetos de la apropiación original no son los individuos, sino las estirpes a las que representan; otra, proceder a una redistribución, a una nueva apropiación original, tantas veces como sea necesario por haber cambiado el censo de los que tienen derecho a participar en ella. En el primer caso, los individuos que participan en la apropiación original, o más bien los hogares a los que representan, son sucedidos por las generaciones posteriores, con los consiguientes e inevitables resultados de concentración o dispersión de la propiedad a través de la descendencia múltiple o las alianzas matrimoniales, más las transacciones voluntarias inter vivos. Al cabo de más o menos generaciones habrá individuos u hogares que se hayan deshecho o se hayan visto privados de recursos naturales, pero, puesto que nadie nace spontex, todo lo que hay que exigir es que las formas de adquisición sean legítimas. En el segundo caso, sobre el supuesto de que los titulares del derecho a la apropiación original son las personas de cualquier generación (o también, mutatis mutandis, si postulásemos que se trata de los hogares de cualquier generación), habrá que proceder a una redistribución, o a una nueva apropiación, cada vez que el censo aumente, o disminuya, al menos si lo hace de forma apreciable; o, si los recursos apropiados se transmiten por herencia individual o familiar de una generación a otra, cada vez que una nueva hornada de individuos proceda no proporcionalmente de la anterior, es decir, cada vez que la propiedad procedente de unos hogares se diluya por su más rápida proliferación mientras la de otros se concentra por los motivos opuestos.

La forma más parsimoniosa de hacer esto es, naturalmente, dotar a cada nuevo individuo $\mathrm{u}$ hogar de su parte alícuota de los recursos naturales. Incluso si esto se hiciera simplemente con los que van dejando libres los que abandonan la sociedad, las desigualdades intergeneracionales producidas por los cambios de densidad demográfica deberían manifestarse en forma suave y gradual, autocorrigiéndose y volviendo a aparecer en un proceso inagotable. Pero, por suerte, ese magnífico invento que es el dinero permite un mecanismo todavía más flexible: dotar a cada nuevo miembro de la sociedad de bienes y recursos en un monto equivalente — de valor igual — al de los recursos naturales que, en caso de producirse en ese momento la apropiación original, tendría derecho a apropiarse para sí. 


\section{CUADRO 2}

\section{Apropiación original y dotación inicial}

\begin{tabular}{|c|c|c|}
\hline & Apropiación original & Dotación inicial \\
\hline Concreción & Parcela de tierra & Bienes y servicios diversos \\
\hline Parte alícuota & $\begin{array}{l}\text { De la tierra y sus recursos, en térmi- } \\
\text { nos físicos }\end{array}$ & Del valor de los recursos naturales \\
\hline Tipo de derecho & $\begin{array}{l}\text { Natural, } \\
\text { sobre la naturaleza }\end{array}$ & $\begin{array}{l}\text { Social, } \\
\text { ante la sociedad }\end{array}$ \\
\hline Basada en & $\begin{array}{l}\text { La disponibilidad de recursos natura- } \\
\text { les libres }\end{array}$ & $\begin{array}{l}\text { La equivalencia de recursos naturales } \\
\text { y productos del trabajo }\end{array}$ \\
\hline Flexibilidad & $\begin{array}{l}\text { Mínima: requiere deshacer cada } \\
\text { apropiación anterior }\end{array}$ & $\begin{array}{l}\text { Máxima: actualiza constantemente la } \\
\text { apropiación }\end{array}$ \\
\hline Funciona bien & Intrageneracionalmente & Intergeneracionalmente \\
\hline
\end{tabular}

En una sociedad en la que la naturaleza es ya un recurso escaso, y en la que una buena parte de la humanidad vive relativamente apartada de ella y no tiene necesariamente interés en disfrutarla en su forma original, parece que lo más razonable es considerar el derecho a la parte alícuota de los derechos naturales como un derecho sobre la parte alícuota de su valor. Así, la apropiación original deja paso a una dotación inicial para todos los nuevos miembros de la sociedad. Podríamos decir también que un derecho natural (un derecho sobre la naturaleza) es sustituido por un derecho social (un derecho sobre la sociedad) equivalente y con el mismo fundamento, aunque exigible y otorgable por un mecanismo distinto. Pues bien: ¿por qué no admitir que esto es precisamente la ciudadanía social, el conjunto de los llamados derechos sociales que la sociedad garantiza a cualquiera de sus miembros en cualesquiera circunstancias: educación obligatoria, asistencia sanitaria mínima, etc., así como también los bienes públicos? La cuestión, entonces, sería simplemente de cuantía, aunque no por ello, sin duda, sería una cuestión menor. Por otra parte, ningún derecho vale más ni más allá que el poder dispuesto a defenderlo, de manera que, en la actual configuración política de las sociedades, y tanto en forma de apropiación original como bajo la figura de los derechos sociales, los derechos individuales sobre los recursos naturales no tienen ni podrían tener otra realidad que la que puedan alcanzar en el ámbito de cada sociedad nacional.

Finalmente, los recursos naturales, al igual que los productos del trabajo, podrían consumirse como bienes y servicios de consumo, dejarse permanecer inactivos o aportarse como factores a la producción. Si la opción fuese esta 
última, y establecido algún tipo de equivalencia con los productos del trabajo (por el juego del mercado, por una decisión burocrática, por un referendo o por cualquier otro sistema), su contribución al producto nuevo daría a sus propietarios un derecho sobre éste: la renta de la tierra. Una vez más, como en los guiñoles infantiles, surge una figura poco querida, esa a cuyo apaleamiento siguen siempre los aplausos: el terrateniente, con un curriculum vitae poco recomendable desde la perspectiva de la igualdad y la justicia; pero lo que le otorga su peor perfil no es haber puesto su parte alícuota de los recursos naturales a producir — que quizá sea lo único bueno que se pueda esperar de él一, sino poseer mucho más que su parte alícuota debido a mecanismos que no podrían reducirse a sus personales propensiones al trabajo o al ahorro, sino, casi con total seguridad, a un pasado familiar iniciado con la rapiña y prolongado a través de la explotación y de la herencia.

Pasaríamos, así, de una distribución pro labore de los productos del trabajo a una distribución pro rata de los productos de la cooperación, sobre las cuales todavía debemos añadir la observación de que ambas corresponden al estadio de la producción para el cambio, pero la primera lo hace al subestadio de la producción independiente y la segunda al de la producción cooperativa. En este sentido, podría verse la teoría del valor-trabajo, en la versión de Marx y, sobre todo, en la de otros socialistas como Hodsgskin (1825) y Thompson (1825), que pretendían explícitamente que el trabajador se apropiara de la totalidad del producto, como un residuo de los valores artesanales, del modo de producción mercantil, proyectado sobre la época industrial, sobre el modo de producción capitalista. Marx, aun sosteniendo que sólo el trabajo vivo creaba valor, rechazó de forma explícita esta pretensión ${ }^{15}$, pero no a favor de los propietarios de los demás factores, sino de la sociedad en general.

¿Cómo establecer la equivalencia entre los recursos naturales y los productos del trabajo? El problema no se plantearía si los recursos naturales fuesen los únicos factores de producción, o los aplastantemente predominantes, como lo eran en las sociedades agrarias, pues la cuestión sería siempre dotar a los individuos (personas u hogares) de recursos bastantes, de factores suficientes, no de su valor equivalente (a esto responde la redistribución periódica de la tierra en algunas sociedades agrarias). Una vez que los recursos naturales son sólo una parte, y decreciente, tanto de la riqueza social total como de los factores de producción en particular, no hay razón alguna, como ya hemos indicado, para que no sean sustituidos por su valor equivalente, con la consiguiente ganancia de flexibilidad. La cuestión, entonces, es cuál es el valor de los recursos naturales, a qué cantidad absoluta o relativa de la riqueza social total equivale la parte alícuota de los recursos naturales. Una solución, por supuesto, la da el merca-

15 Véase su diatriba, por lo demás algo forzada, contra la idea lassalliana del «reparto equitativo del fruto del trabajo» (Marx, 1875: 17), del cual habría que deducir la amortización, la inversión, un fondo asegurador, la administración, el equipamiento colectivo y los fondos para los incapaces. 
do: el precio de la tierra, pero sabemos que está viciada de antemano por la distribución inicial de las dotaciones ${ }^{16}$. La solución alternativa es un precio político que podría calcularse en cualquier momento teniendo en cuenta su escasez, su precio de mercado, las perspectivas de crecimiento demográfico y/o cualquier otro elemento que pudiera considerarse oportuno.

Ahora bien: si existe fundamento para establecer un precio político a la parte per capita de los recursos naturales, ¿por qué no establecer directamente el valor de la ciudadanía nuda? Pues esto es, precisamente, lo que la sociedad hace cuando acuerda que, por el mero hecho de nacer y vivir, sus miembros tienen ciertos derechos sociales efectivos: cierto período de escolarización, cierto nivel de asistencia sanitaria no contributiva, una especie de seguro no contributivo contra el desempleo o la incapacidad (los subsidios y pensiones no contributivos), algún grado de protección policial y jurídica, etc. Por supuesto que se trata de un grado muy bajo, muy por debajo de lo que sería su parte alícuota en la riqueza, incluso de lo que sería una participación típica en los niveles inferiores de su distribución a través del trabajo, pero también, sin duda, por encima de lo que, en un mundo de recursos naturales limitados, densidad demográfica creciente y productividad agraria muy inferior a la de la industria e incluso a la de los servicios, obtendrían del aprovechamiento individual y directo de su parte alícuota de la tierra sin cooperación social y sin la infraestructura y la tecnología que la cooperación de su generación y de las precedentes han creado, es decir, en una economía de subsistencia.

Permítaseme, de pasada, una observación: el derecho natural a la parte alícuota de la naturaleza, o a su valor equivalente, sería el único fundamento posible, en términos de derechos, para un ingreso universal incondicional, es decir, para un ingreso ofrecido a todos sin ninguna contrapartida contributiva y sin otra condición que la ciudadanía. Éste es, por cierto, el mismo fundamento que le atribuyó Thomas Paine ${ }^{17}$, con independencia de las fórmulas que propuso para realizarlo ${ }^{18}$. Sería la consecuencia del reconocimiento del derecho a apartarse de la sociedad, pero sin hacer a ésta incurrir en costes extraordinarios. El individuo tiene derecho a apartarse de la sociedad con su parcela de tierra, pero, puesto que para la sociedad sería demasiado complejo y costoso

${ }^{16}$ Si no, no habría inconveniente alguno en servirse de él como propone Dworkin, como una gran subasta: «La igualdad de recursos supone que los recursos destinados a la vida de cada persona deberían ser iguales. Ese objetivo necesita una métrica. La subasta [el mercado] propone lo que la prueba de la envidia asume de hecho: que la verdadera medida de los recursos sociales dedicados a la vida de una persona se fija preguntando cuán importantes, de hecho, son esos recursos para los demás.» Pero él mismo añade: «Por supuesto, es capital en este argumento, y en esta conexión entre el mercado y la igualdad de recursos, que la gente acceda al mercado en términos de igualdad [es decir: con igual capacidad de compra]» (Dworkin, 1981: 289).

17 «[E]l primer principio de la civilización debería haber sido, y debería ser todavía, que la condición de toda persona nacida en el mundo después de comenzar un estado de civilización no debería ser peor que si hubiese nacido antes de ese período» (Paine, 1795).

${ }_{18}$ Paine propuso una dotación inicial, al llegar a los 21 años, y una pensión vitalicia a partir de los 51 . 
que lo hiciera efectivamente con su parcela, le ofrece la opción única de recibir el equivalente a lo que obtendría de su parcela sin mediar la sociedad, es decir, en régimen de economía de subsistencia. Como se ve, un ingreso universal de este tipo no promete mucho a nadie ${ }^{19}$, pero es que la sociedad tiene derecho a pensar que, en relación con ella, hay que estar a las duras y a las maduras.

Por otra parte, parece razonable que el individuo tenga derecho a apartarse con su parcela, pero no con la mesa puesta de por vida, sea en términos reales o equivalentes. Excepto en el tan añorado como inexistente paraíso perdido, no se tiene noticia de que la apropiación de la naturaleza permitiera jamás al hombre prescindir del trabajo. Creo, pues, que lo que puede corresponder hoy a la apropiación original de la naturaleza es el acceso a los factores, más que un flujo constante de ingresos sin ninguna contrapartida (la renta incondicional). Este último correspondería, ciertamente, al imaginario paraíso en que los frutos, tan sabrosos ya entonces como después de varios milenios de agricultura, podrían ser cogidos de los árboles con sólo estirar la mano. A la apropiación real de la naturaleza corresponde más bien la dotación inicial o el acceso permanente a los recursos, es decir, a la posibilidad de hacerlos producir con el trabajo. En consecuencia, su forma factible y justificable hoy sería una dotación inicial y/o una oportunidad garantizada de empleo de baja intensidad y baja remuneración.

\section{INCENTIVOS Y DESIGUALDAD}

Si comparamos la distribución real con cualquier idea que tengamos de lo que podría resultar de la apropiación igualitaria de los recursos naturales y la apropiación equitativa de los resultados de la producción, incluso cualquiera que sea la variante de cada una de éstas que adoptemos, es probable que todavía difieran de forma sustancial. Esto puede significar que la distribución real es injusta o, simplemente, que no sólo depende de criterios de justicia pero sin que ello implique necesariamente que es injusta. Puede suceder, sin ir más lejos, que existan buenos motivos para tolerar y hasta para favorecer cierto grado de injusticia, socialmente consensuado y, por tanto, legítimo. Lo justo es lo justo, pero no necesariamente lo mejor.

En otro lugar he mostrado que el resultado (relativo) obtenido por un individuo en un proceso cooperativo puede expresarse mediante la sencilla fórmula:

$$
\rho=\pi \tau_{g}=\pi \tau_{i} \tau_{x}
$$

19 «La civilización [...] ha actuado de dos formas: para hacer a una parte de la sociedad más rica, y a la otra más pobre, que lo que habría correspondido a cada una en un estado de naturaleza» (Paine, 1795). 
donde $\rho$ es su tasa individual de rendimiento (el cociente entre lo que inicialmente aporta a la producción cooperativa y lo que finalmente recibe del resultado común), $\pi$ la productividad del proceso (el cociente entre el valor del producto y el valor de los factores), $\tau_{i}$ la tasa de explotación interna (el cociente entre su parte en el total de los factores y su parte en el resultado de la organización en el proceso de circulación, es decir, en el intercambio con el entorno - por ejemplo, en el precio obtenido por su producción-), $\tau_{x}$ la tasa de explotación externa (el cociente entre el resultado de la organización en la circulación y el producto del proceso de producción) y $\tau_{g}$ la tasa de explotación global (el producto de las tasas de explotación interna y externa) ${ }^{20}$. Puede que individuos firme u obsesivamente defensores de los principios busquen sobre todo que las distintas $\tau$ se mantengan iguales a la unidad, es decir, que no haya explotación, pero lo más probable es que busquen simplemente maximizar $\rho$, aunque ello pase por aceptar una disminución de $\tau$, y particularmente que acepten aumentar $\rho$ a través de aumentos de $\pi$ y/o de $\tau_{x}$ obtenidos a costa de disminuciones proporcionalmente no tan intensas de $\tau_{i}$.

Supóngase, simplemente, un trabajador en una empresa. Sus resultados pueden expresarse en forma de tasa de rendimiento, en el sentido antes explicado, para evitar que dependan de su propensión al trabajo o al ocio, es decir, en unos términos que los hagan comparables para todos los trabajadores. Estos resultados dependen, por un lado, de su posición relativa en la empresa, que se resume en su tasa de explotación interna; por otro, de la productividad de la empresa, que expresa su capacidad de convertir eficazmente los factores en producto; finalmente, de la posición de la empresa en el mercado, es decir, de sus posibilidades de vender bien el producto, a lo que llamamos su tasa de explotación externa. El trabajador preferirá, naturalmente, una tasa de explotación interna que le sea desfavorable pero resulte sobrecompensada por la productividad y/o la tasa de explotación externa a una tasa de explotación interna que le sea favorable pero no resulte compensada o sólo resulte infracompensada por éstas, porque lo que cuenta, al final, es qué salario obtiene por qué trabajo. Por supuesto que preferiría que todo le fuese favorable - lo que equivale a decir que probablemente preferiría ser el propietario o el jefe de una empresa rentable-, pero, si ha de elegir entre distintas combinaciones, lo que cuenta es el resultado final, y este resultado bien puede avalar, desde su punto de vista, combinaciones que reúnan la injusticia hacia él por parte de otros participantes (explotación interna) con la injusticia hacia el público (explotación externa) y la eficacia (productividad).

El problema es que este ejemplo ilustra las condiciones en que los individuos pueden aceptar racionalmente, desde el punto de vista de sus propios intereses, la injusticia, pero no es susceptible de agregación. Efectivamente, podemos suponer que, a medio y largo plazo, la productividad de las organizaciones se iguala, lo que significa que la tasa de productividad ponderada para todos

${ }^{20}$ Véase Enguita (1997). 
los participantes de todas las empresas es necesariamente la unidad; por otra parte, las tasas de explotación externa se compensan, pues lo que gana el vendedor tiene que perderlo el comprador, y viceversa, de modo que la tasa de explotación agregada y ponderada es también igual a la unidad. La cuestión, entonces, es que el razonamiento que resulta válido a escala de cada unidad productiva no lo es a escala de la sociedad global. De hecho, nos habríamos encontrado incluso antes con este problema si, en vez de considerar la explotación o la justicia distributiva en la producción, la hubiésemos considerado en la circulación: ¿por qué la sociedad acepta un procedimiento de circulación en el que siempre son posibles transacciones injustas, aunque sean transacciones libres? O, aplicado a nuestro entorno histórico y social: ¿por qué la sociedad acepta el mercado? Una posible respuesta, por supuesto, es que éste se impone por la fuerza, y no es una respuesta desprovista de fundamento - como lo muestra la diligencia con que se ha utilizado siempre la diplomacia de las cañoneras para abrir paso al libre comercio, o la feroz defensa del mercado por las clases propietarias $-{ }^{21}$. Sin embargo, todo parece indicar que el mercado, al menos en nuestro entorno - y, a la larga, en cualquier entorno-, se basa mucho más en el consenso que en la fuerza. En todo caso, podemos eludir este problema de segundo orden planteando la pregunta de otro modo: ¡en qué se basa el consenso en torno al mercado, un mecanismo de circulación en el que, aparentemente, la mayoría de la gente pierde?

La clave de la solución es que, si nos estamos interrogando sobre el conjunto de la sociedad, la respuesta no puede venir en términos de participaciones comparadas. Cuando nos preguntábamos sobre en qué condiciones podría aceptarse la explotación en un proceso de producción cooperativa (explotación interna) hubimos de buscar la respuesta en el entorno externo de este proceso (explotación externa) o en el contenido sustantivo de las participaciones (productividad), las dos variables que afectan al tamaño global de la tarta. Cuando nos preguntamos sobre la sociedad global desaparece la posibilidad de remitirnos al entorno ${ }^{22}$ y sólo nos queda la de hacerlo al contenido material. Ciñéndonos a nuestro ejemplo, esto significa que la respuesta no puede venir dada en términos de valor (o, por decirlo al modo clásico, de valor de cambio), sino en términos de bienestar material (o sea, en las dos variantes de la terminología clásica: de valor de uso o de utilidad). En otras palabras, los individuos aceptarían el mercado, aun suponiendo que todos supieran que la mayoría pierden valor en él, porque ganan o creen ganar en la satisfacción de sus necesidades.

Este tipo de apertura a la desigualdad es la del segundo principio rawlsiano: «las desigualdades sociales y económicas, por ejemplo las desigualdades de

21 «[M]ientras ese sistema [el liberalismo económico, o sea, el mercado] no se haya establecido, los liberales deberán pedir y pedirán sin vacilar la intervención del estado con el objetivo de establecerlo y, una vez establecido, con el de mantenerlo» (Polanyi, 1974: 149).

22 En realidad, entre la unidad de la producción cooperativa y la sociedad propiamente global, es decir, planetaria, media la sociedad nacional, pero podemos ignorar este nivel intermedio en aras de la simplicidad. 
riqueza y autoridad, sólo son justas si producen beneficios compensadores para todos y, en particular, para los miembros menos aventajados de la sociedad" (Rawls, 1971: 32). Sin embargo, la satisfacción de este principio no es suficiente para que deje de haber explotación — siendo más exactos: no tiene ninguna relevancia al respecto, al menos en sentido estricto-. Rawls no es muy explícito sobre qué puedan ser esos beneficios compensadores, pero podemos imaginar tres interpretaciones, según pensemos en benéficos compensadores para los miembros menos aventajados de la relación concreta, del tipo de relación o del conjunto de relaciones en que se inserta esa relación. En otros términos, según que el principio de diferencia deba cumplirse en el caso, en la institución o en la estructura.

La primera interpretación, que los beneficios compensadores sean para quienes participan en cada relación concreta, puede entenderse, a su vez, de dos maneras: que los resultados superen cierto umbral absoluto - por ejemplo, el de un rendimiento igual o superior a la unidad, o cualquier otro- o que sean mejores que en las otras opciones en presencia. En la segunda variante estaríamos simplemente ante el requisito de la voluntariedad de las relaciones económicas, suponiendo a los agentes que entran en ellas un mínimo nivel de información. Efectivamente, el asalariado se asalaría, el vendedor vende, el comprador compra, etc., porque, en el peor de los casos, cree que va a estar algo mejor que si no lo hiciera $-\mathrm{y}$ no hay motivo para dudar del acierto de esta suposición-, y lo hacen en la mejor de las opciones a su alcance. Cualquier relación voluntaria se establece porque ambas partes creen mejorar con ella, pero esto reduciría el principio rawlsiano de la diferencia a la sencilla pretensión, tan cara a la economía neoclásica, de que si la relación es voluntaria, o si beneficia a ambas partes en las circunstancias dadas (lo que es exactamente lo mismo, supuesta la racionalidad instrumental de los actores), es inobjetable. Lo que Nozick (1974: 163), con su brillante cinismo, llama "actos capitalistas entre adultos que consienten». Sin embargo, para este viaje no hacían falta alforjas. Si podemos interrogarnos sobre la existencia de la explotación como relación distinta e independiente de la opresión es porque partimos del hecho de que puede ser parte integrante de una relación voluntaria entre individuos libres; de hecho, partimos de que, en una sociedad abierta, en general lo es, no en el sentido de que la gente desee ser explotada, lo cual constituiría un absurdo lógico, sino en el sentido de que se embarca voluntariamente en relaciones en las que resulta explotada porque, normalmente, el resultado obtenido es, pese a ello, mejor que el que obtendría absteniéndose de hacerlo; o bien, lo que sería otro caso pero probablemente minoritario, porque no sabe que es así, ignorancia que sólo podría estar en la base de su aceptación en el supuesto de que, de no ser por ella, pudieran elegir u obtener otro tipo de relaciones o ninguna sin merma de su bienestar.

En la primera variante, la legitimidad de la relación vendría dada por el resultado obtenido por el individuo en cada caso, lo que quiere decir que existiría en unos casos sí y en otros no, aun tratándose de la misma relación, o, lo 
que es lo mismo, que la aceptabilidad de la relación sería contemplada de un modo puramente instrumental: bien está lo que bien acaba, pero nada más, o cada uno cuenta la fiesta según le va en ella, etc. Sin embargo, eso no es lo que solemos llamar legitimidad, pues ésta — como la justicia- ha de ser una cualidad procedimental, no sustantiva. No cabe pensar, en nuestro ejemplo, que el mercado o la compraventa de fuerza de trabajo sean legítimos o ilegítimos según el precio. En suma, el criterio casuístico es demasiado estrecho y, por esencia, no puede servir de base para una norma moral ni de convivencia.

En la tercera interpretación estaríamos ante una especie de justificación de la desigualdad por el desarrollo general, pero el problema con esta formulación es establecer relaciones de causa-efecto entre un determinado tipo de desigualdad y la posición de los miembros menos aventajados. Tal vez permita - aunque me parece harto dudoso- sacar conclusiones sobre las grandes pautas de organización de la sociedad (por ejemplo, mercado frente a planificación, capitalismo frente a socialismo, etc. ${ }^{23}$ ), pero me parece prácticamente imposible, con los instrumentos a nuestro alcance, utilizar este principio para juzgar la aceptabilidad o no de formas o grados concretos de desigualdad como los que se discuten dentro del ámbito de una forma social aceptada ${ }^{24}$. En otras palabras, si aplicamos el principio de diferencia a conglomerados demasiado amplios de instituciones es casi seguro que se mezclarán el grano y la paja - lo necesario y lo innecesario- o incluso el grano y la cizaña - lo conveniente y lo inconveniente- - de modo que la presencia de la segunda resulte legitimada por los efectos del primero. Creo, sin embargo, que ésta es la interpretación que sostiene o está más cerca de sostener el propio Rawls cuando afirma que su segundo principio se aplica al sistema del derecho público ${ }^{25}$, pero aquí no estamos obligados por una jurisprudencia subjetiva.

La vía intermedia consiste en que el principio de diferencia no se aplique a tal o cual relación desigual, sino a tipos de relaciones desiguales, es decir, a instituciones: admitimos, por ejemplo, recompensar generosamente a los inventores, a cualquier inventor, mediante el sistema de patentes, porque participamos de la convicción de que estimular la innovacion técnica mejora las condiciones

${ }^{23}$ Así lo hace Berger (1986: 48): «Si se quiere mejorar las condiciones materiales de la gente, especialmente las de los pobres, es aconsejable optar por el capitalismo. Si se quiere modernizar, bajo cualquier forma de organización socioeconómica (capitalista o socialista), probablemente habrá que establecer una medida considerable de desigualdad material.»

${ }^{24}$ Por ejemplo, en el ámbito de una economía de mercado, o mixta, o planificada. El colectivismo burocrático también tuvo su dosis de debate sobre el grado de desigualdad aceptable en aras del crecimiento económico global: en la Unión Soviética, desde los escritos de Lenin sobre la emulación socialista, pasando por el debate sobre la NEP o el stajanovismo, hasta las reformas Lieberman-Trapeznikov; en Cuba, con el debate sobre «el socialismo y el hombre» auspiciado por Ernesto Guevara.

25 «[S]e aplica al sistema del derecho público y de las leyes públicas (sistema que goza de notoriedad pública); no a las transacciones y a las distribuciones particulares, ni a las decisiones de los individuos y de las asociaciones, sino al trasfondo institucional que envuelve a esas transacciones y decisiones» (Rawls, 1993: 319). 
generales de vida de la humanidad, en particular las de su porción menos favorecida, y esta convicción general nos exime de la tarea de probar que así lo haga tal o cual invención particular; o a los artistas, porque su trabajo mejora la calidad de vida de las personas, sin preguntarnos si el trabajo de tal o cual artista particular es una mejora — de gustibus non est disputandum - ni si llega a más o menos gente; o a los empresarios, porque estimulando su ambición se estimula la productividad y, con ello, el tamaño de la tarta a repartir y el bienestar de todos. Se consideran justas, siguiendo a Rawls, o simplemente aceptables y legítimas, a mi entender, aquellas desigualdades que mejoran de algún modo la suerte de los más desfavorecidos. Premiamos, entonces, las cualidades excepcionales, sean innatas o cultivadas, de todos aquellos que nos permiten alcanzar cotas de bienestar que no habríamos alcanzado sin ellos.

Pero no debe confundirse la eficacia con la igualdad, ni las recompensas instrumentales con los derechos individuales, ni la legitimidad con la justicia. Igual que en los cuentos de la época estamental el rey ofrece la mitad de su reino, o la mano de la princesa, a quien la salve del dragón, igual puede la sociedad ofrecer la riqueza por una hermosa melodía, un bello cuadro o un útil sistema operativo: es un aspecto de lo que hace el mercado (y antes hacían los mecenas). Ahora bien, esto es sólo parte de lo que sucede, en realidad un subproducto, porque lo que el mercado realmente hace es permitir a cada cual obtener por lo que posee todo lo que sean capaces de pagar quienes lo desean, no importa qué sea aquello, ni cómo se obtuviera, ni cuántos sean éstos, ni cuál sea su grado de necesidad o deseo. Las mismas virtudes del mercado como mecanismo de incentivación son precisamente sus vicios como instrumento de justicia distributiva ${ }^{26}$, y probablemente pueda decirse lo mismo de cualquier otro sistema de distribución de retribuciones y recompensas: que la retribución justa nunca es recompensa suficiente para ir un poco más lejos.

En tal caso, si las desigualdades admitidas por el segundo principio no proceden de la justicia sino de la conveniencia, aunque estén dotadas de la legitimidad que les concede su aceptación social, no hay motivo para admitirlas en cualquier cantidad y de cualquier calidad, porque son legítimas pero eso no las convierte en justas. En otras palabras, se pueden admitir las desigualdades que mejoran la situación general, o como mínimo la de los miembros o los actores menos favorecidos, pero no hay motivo para que todo lo que queda por encima de este requisito mínimo vaya a parar a la cuenta de los más favorecidos. Se puede, como sugiere el principio rawlsiano, admitir la diferencia; pero si el criterio es de carácter instrumental también se podrá, de un modo u otro, partir

26 «Premios espectaculares, mucho mayores de lo que hubieran sido necesarios para estimular el esfuerzo particular, son arrojados a una pequeña minoría de ganadores, empujando así mucho más eficazmente de lo que lo habría hecho una distribución más igual y más “justa” la actividad de esa gran mayoría de hombres de negocios que reciben a cambio una compensación muy modesta, o ninguna, o menos que ninguna, y a pesar de ello se esfuerzan al máximo porque tienen los grandes premios a la vista y sobrevaloran sus posibilidades de conseguirlos también» (Schumpeter, 1942: 73-74). 
la diferencia. Desde el punto de vista de la economía neoclásica, esto significa, sin lugar a dudas, explotar a los miembros o actores mejor situados, ya que se les impediría sacar todo el provecho posible de su posición en el mercado (pero no tendría que producir demasiado escrúpulo explotar al explotador). Desde el punto de vista de una teoría del valor (una norma de distribución) como la aquí planteada, o parecida, el problema se reduce a cuánta desigualdad hay o habría que tolerar para conseguir el objetivo de eficacia ${ }^{27}$.

El segundo principio rawlsiano de la justicia, o principio de diferencia, debería entonces ser parcialmente reformulado. Según Rawls: «La estructura básica debería permitir desigualdades organizativas y económicas en la medida en que éstas contribuyeran a mejorar la situación de todo el mundo, incluida la de los menos favorecidos, siempre que esas desigualdades fueran compatibles con la igual libertad y con la igualdad equitativa de oportunidades» (Rawls, 1993: 318). La formulación de Rawls permite admitir cualquier grado de desigualdad siempre y cuando vaya acompañada de alguna mejora de la situación general o, como mínimo, de la situación de los menos favorecidos. Aunque en la cita anterior y otras la expresión "en la medida» pueda prestarse a confusión, Rawls no alude a un límite cuantitativo, sino a una condición cualitativa. Las desigualdades sociales son aceptables si y sólo si contribuyen a mejorar la situación de los más desaventajados. Una clara demostración de lo poco exigente que resulta, en realidad, el segundo principio rawlsiano la proporciona el propio autor cuando toma como referencia la equidivisión de los bienes primarios, que sería el equivalente a la apropiación original igualitaria.

«Los dos principios [de la justicia] expresan la idea de que nadie debería tener menos de lo que recibiría en una equidivisión de los bienes primarios, y de que, cuando la fertilidad de la cooperación social permita una mejora general, entonces las desigualdades sociales tienen que trabajar en beneficio de aquellos cuya posición social haya sido menos mejorada, tomando como punto de referencia la equidivisión» (Rawls, 1993: 320).

La reformulación que aquí se propone podría expresarse así: las desigualdades sociales son aceptables en la medida y sólo en la medida en que resulten necesarias para mejorar la situación general, o al menos la de los más desfavorecidos. La medida representa aquí un límite cuantitativo, aunque presupone, por supuesto, la condición cualitativa de que tales desigualdades contribuyan de algún modo a mejorar la situación de todos o la de los peor situados, es decir, el principio rawlsiano de la diferencia (incluyendo, si se quiere, la igual-

${ }^{27}$ Lo dicho no implica nada sobre dónde y cómo partir la diferencia. Se puede considerar, como lo ha hecho la mayor parte de la economía a partir de Mill, que no se debe interferir la asignación de los factores de la producción a través del mercado, pero que se puede intervenir la distribución. Esto es lo que, en cierta medida, hace el Estado social. 
dad de oportunidades, aunque no voy a detenerme en esto). Podríamos llamar a esto el principio de recompensa, por cuanto la sociedad recompensa por su especial contribución a ciertos individuos aun cuando con ello tenga que aceptar desigualdades de las que, no obstante, se siente compensada por esa excepcionalidad. Representa, respecto del principio rawlsiano, una vuelta de tuerca más: no se admite más desigualdad que la estrictamente necesaria y hasta donde sea estrictamente necesaria, porque no tiene otro papel que el de un incentivo material, algo ajeno a la justicia. Esto no prejuzga la forma de su aplicación, que no tendría por qué consistir en una limitación a priori de la desigualdad (prohibición de los negocios privados, salarios máximos, etc.), sino que podría basarse en una corrección a posteriori de sus efectos (política fiscal redistributiva). Las similitudes y diferencias entre ambas normas se esquematizan en el cuadro 3.

\section{CUADRO 3}

\section{Principio de diferencia y principio de recompensa}

\begin{tabular}{lll}
\hline & \multicolumn{1}{c}{ Principio de diferencia } & \multicolumn{1}{c}{ Principio de recompensa } \\
\hline Criterio de & Justicia & Eficacia \\
\hline $\begin{array}{l}\text { Tiene carácter } \\
\text { de }\end{array}$ & Derecho & Incentivo \\
\hline $\begin{array}{l}\text { Condición cua- } \\
\text { litativa }\end{array}$ & $\begin{array}{l}\text { Mejorar la situación de los menos } \\
\text { favorecidos }\end{array}$ & $\begin{array}{l}\text { Mejorar la situación de los menos } \\
\text { favorecidos }\end{array}$ \\
\hline $\begin{array}{l}\text { Requiere para } \\
\text { los peor situa- } \\
\text { dos }\end{array}$ & $\begin{array}{l}\text { Que mejore su situación en alguna } \\
\text { medida }\end{array}$ & $\begin{array}{l}\text { Que mejore todo lo posible, salvando } \\
\text { el incentivo }\end{array}$ \\
\hline $\begin{array}{l}\text { Otorga al me- } \\
\text { jor situado }\end{array}$ & $\begin{array}{l}\text { Todo menos alguna mejora para los } \\
\text { peor situados }\end{array}$ & $\begin{array}{l}\text { Sólo el incentivo suficiente para } \\
\text { lograr la mejora }\end{array}$ \\
\hline $\begin{array}{l}\text { Límite máximo } \\
\text { El aumento global menos la mejora } \\
\text { mínima }\end{array}$ & El incentivo \\
\hline $\begin{array}{l}\text { Parte la diferen- } \\
\text { cia }\end{array}$ & A favor del mejor situado & A favor del peor situado \\
\hline
\end{tabular}

\section{RECOLECCIÓN, RETRIBUCIÓN Y RECOMPENSA}

El conjunto de recursos al que toda persona puede acceder legítimamente, entonces, podría descomponerse en tres grandes categorías: su recolección, su 
retribución y su recompensa. Su recolección es simplemente el ejercicio de su derecho a la apropiación de los recursos naturales, su parte alícuota en lo que ya estaba ahí con anterioridad a él y a cualquier otro, o con independencia de él y de cualquier otro. Su retribución es la contrapartida por su participación en la producción medida por su esfuerzo, es decir, por su trabajo (y, eventualmente, por su espera), y proporcional al mismo. Su recompensa es el premio extraordinario a su aportación especial a la producción o mejora de los recursos sociales, aquello a lo que se le otorga derecho por encima de su esfuerzo. El cuadro 4 resume estas y otras características de los tres grupos de recursos citados.

\section{CUADRO 4}

\section{Los recursos legitimos}

\begin{tabular}{|c|c|c|c|}
\hline & Recolección & Retribución & Recompensa \\
\hline $\begin{array}{l}\mathrm{Da} \text { al individuo acce- } \\
\text { so a }\end{array}$ & Los recursos naturales & $\begin{array}{l}\text { Los productos del tra- } \\
\text { bajo }\end{array}$ & $\begin{array}{l}\text { Las aportaciones ex- } \\
\text { traordinarias }\end{array}$ \\
\hline \multirow[b]{2}{*}{ Corresponde a } & Reproducción & Producción & Innovación \\
\hline & $\begin{array}{l}\text { Subsistencia, autosu- } \\
\text { ficiencia }\end{array}$ & $\begin{array}{l}\text { División del trabajo, } \\
\text { cooperación }\end{array}$ & $\begin{array}{l}\text { Crecimiento, desarro- } \\
\text { llo, excedente }\end{array}$ \\
\hline $\begin{array}{l}\text { Proporciona a la so- } \\
\text { ciedad bienes }\end{array}$ & $\begin{array}{l}\text { Que nadie ha produ- } \\
\text { cido }\end{array}$ & $\begin{array}{l}\text { Que cualquiera puede } \\
\text { producir }\end{array}$ & $\begin{array}{l}\text { Que pocos pueden } \\
\text { producir }\end{array}$ \\
\hline Se mide por & Parte alícuota & Tiempo de trabajo & Incentivo suficiente \\
\hline $\begin{array}{l}\text { Criterio de distribu- } \\
\text { ción }\end{array}$ & $\begin{array}{l}\text { Igualdad absoluta } \\
\text { (identidad) }\end{array}$ & $\begin{array}{l}\text { Igualdad relativa } \\
\text { (proporcionalidad) }\end{array}$ & $\begin{array}{l}\text { Principio de recom- } \\
\text { pensa (incentivo) }\end{array}$ \\
\hline Forma separada & $\begin{array}{l}\text { Apropiación original } \\
\text { Derechos sociales }\end{array}$ & $\begin{array}{l}\text { Salario } \\
\text { Precio }\end{array}$ & $\begin{array}{l}\text { Renta de escasez } \\
\text { Beneficio }\end{array}$ \\
\hline Base individual en & Existencia & Esfuerzo & Capacidades \\
\hline Requiere capacidad & Ninguna & Normal & Especial \\
\hline $\begin{array}{l}\text { Tipo de oportunidad } \\
\text { individual }\end{array}$ & $\begin{array}{l}\text { Garantía (segura: lo } \\
\text { recibe en todo caso) }\end{array}$ & $\begin{array}{l}\text { Derecho (efectivo: } \\
\text { sólo se pierde por } \\
\text { renuncia al uso) }\end{array}$ & $\begin{array}{l}\text { Oportunidad (abierta: } \\
\text { nadie le impide hacer- } \\
\text { lo) }\end{array}$ \\
\hline $\begin{array}{l}\text { Tipo de derecho a los } \\
\text { recursos }\end{array}$ & $\begin{array}{l}\text { Derecho absoluto, } \\
\text { incondicional }\end{array}$ & $\begin{array}{l}\text { Derecho potestativo, } \\
\text { condicional }\end{array}$ & $\begin{array}{l}\text { Facultad jurídica, pro- } \\
\text { tegida }\end{array}$ \\
\hline
\end{tabular}


La recolección corresponde a la reproducción en sentido estricto. No produciendo, la humanidad consume los recursos naturales y, en el proceso, se reproduce ella misma y se reproduce la naturaleza. Sería la caza-recolección en su forma más elemental, pues es dudoso que, durante la existencia del hombre como tal, haya podido jamás vivir éste en exclusiva disfrutando de los recursos naturales, sin mediación alguna del trabajo ${ }^{28}$. Es un mero reparto de lo preexistente, de lo que nadie ha producido, por lo que la apropiación por un individuo simplemente limita las posibilidades de apropiación de los otros. La retribución, es decir, la apropiación según el trabajo (vivo o muerto) o según el esfuerzo (de hacer o de no hacer), da acceso a los recursos producidos, por uno mismo o por otro. Corresponde a la producción propiamente dicha, desde la autosuficiencia hasta la división del trabajo y la cooperación. Permite apropiarse del producto del propio trabajo y, lo que es más importante, del producto equivalente del trabajo de otro; en suma, de lo que cualquiera podría producir en ciertas circunstancias pero no cualquiera produce en las circunstancias existentes. La recompensa, en fin, corresponde a lo que la sociedad valora como aportaciones extraordinarias, y permite a su beneficiario apropiarse de más de lo que corresponde propiamente a su esfuerzo y, al resto de la sociedad, en uno $\mathrm{u}$ otro grado, disponer de lo que pocos pueden y ninguno querría, sin tal incentivo, producir ${ }^{29}$.

La recolección debe obedecer a la igualdad absoluta y supone así un simple reparto estrictamente idéntico, por lo que su único criterio de medida es la división; la retribución debe plegarse a un criterio de igualdad relativa, de proporcionalidad, de equidad, por lo que su medida es el tiempo de trabajo directo o acumulado $\mathrm{u}$ otro indicador del grado de esfuerzo y privación; la recompensa, finalmente, no tiene por qué obedecer a otra medida que la del mínimo suficiente para suscitar la cooperación buscada en quien la recibe. La recolección puede tomar la forma de apropiación efectiva de los recursos naturales, pero, en una sociedad económicamente desarrollada, también la de una dotación inicial (los derechos sociales) y/o un ingreso ciudadano regular, ambos incondicionales ${ }^{30}$; la retribución tiene su forma típica y, llegado el caso, separada en el salario y en el precio (incluidos el salario del trabajo empresarial, el interés normal o precio del capital, la renta no monopolista de la tierra, etc.); la recompensa, en fin, adopta la forma de beneficios empresariales, salarios que son en realidad rentas de escasez del trabajo altamente cualificado, derechos de autor, etc.

${ }_{28}$ Dudoso pero atractivo, como lo demuestra la ubicuidad del mito del paraíso perdido.

29 No es difícil asociar esto a la concepción schumpeteriana del beneficio empresarial como renta dinámica y temporal, recompensa por la innovación (Schumpeter, 1912).

30 Bajo el epígrafe del ingreso ciudadano pueden incluirse propuestas sustancialmente distintas entre sí. En cualquier caso, nadie debe verse llevado a suponer que las propuestas actualmente en debate tengan algo que ver con lo que aquí se sugiere sobre el derecho a los recursos naturales. Probablemente, la defensa más popular de la propuesta, al menos en el ámbito académico, sea hoy la de Parijs (1994, 1995), quien a su vez se inspira en la propuesta -ésa, sí, mucho más cercana a nuestro razonamiento- de Paine (1795). 
Puesto que lo que se exige al individuo para ser acreedor a cada uno de estos tres tipos de recursos es diferente, sobre esa base se configuran oportunidades y derechos de orden distinto. La recolección de los recursos naturales se basa tan sólo en la existencia, de modo que supone una oportunidad garantizada, segura, sin ningún requisito adicional y, por lo tanto, un derecho absoluto e incondicional. La retribución, que se basa en el trabajo o el esfuerzo, requiere la realización de éste, pero en condiciones tales que todo individuo ha de tener la oportunidad de realizarlo, sin que deba caber otra posibilidad de no hacerlo, para un adulto capaz, que la renuncia expresa a ello (al ejercicio del derecho, porque el derecho en sí es irrenunciable); se trata, pues, de un derecho potestativo, al alcance de la voluntad de cada individuo sin depender del arbitrio de terceros, pero al mismo tiempo condicional en su disfrute, por cuanto el acceso a los recursos requiere la realización del trabajo o esfuerzo ${ }^{31}$. Por último, la posibilidad de optar a la recompensa por una aportación considerada extraordinaria es siempre una oportunidad abierta a todos, a la que no debe oponerse ningún obstáculo negativo ${ }^{32}$, pero también una simple facultad jurídica, protegida en la posibilidad de su ejercicio pero sujeta en su eficacia al reconocimiento de terceros.

\section{REFERENCIAS}

Berger, P. L. (1986): The capitalist revolution, N. York, Basic, 1991.

Enguita, M. F. (1997): «Formas de explotación», Documentos de Trabajo del Departamento de Sociología de la Universidad de Salamanca, Serie Propuestas núm. 4, disponible en http://sociologia.usal.es/mfe/content/documentos/Propuestas/P04.pdf.

Dworkin, R. (1981): "What is equality?», Philosophy and Public Affairs, X, 3, 185-246, y X, 4, 283-345.

George, H. (1879): Progress and poverty, http://www.henrygeorge.org, según la edición de la Robert Schalkenbach Foundation, abreviada por A. W. Madsen.

LOCKE, J. (1690): Ensayo sobre el gobierno civil, Madrid, Aguilar, 1976 $6^{1+2}$.

MACPHERSON, C. B. (1962): The political theory of possesive individualism, Londres, Oxford UP, $1975^{1+6}$.

MarX, K. (1867): El Capital (1867, libro I; 1885, libro II; 1894, libro III), Madrid, Siglo XXI, 8 vols., 1975-1981.

- (1875): Crítica del Programa de Gotha, publ. orig. 1891, Madrid, Aguilera, 1971 $1^{4}$.

${ }^{31}$ Estas condiciones, obviamente, no son satisfechas por el actual reconocimiento constitucional del derecho al trabajo y el seguro de desempleo. Lo serían, si acaso, por un sistema con garantía del empleo a todo el que quisiera trabajar. La forma de compaginar esto con la asignación eficaz de los recursos por el mercado sería dejar funcionar libremente el mercado de trabajo pero ofrecer empleos con una remuneración mínima a los que no pudieran obtener otros, sin ninguna retribución para los que no trabajasen (excepto, claro está, su «recolección»). Un empleo de reserva, más que un seguro de desempleo.

32 Ésta es la primera mitad del principio de diferencia rawlsiano, en la que hasta ahora no nos habíamos detenido: que las posiciones desiguales «se vinculen a empleos y cargos asequibles para todos», que "los cargos y las funciones sean asequibles a todos, bajo condiciones de justa igualdad de oportunidades» (Rawls, 1971: 82, 341). 
NozICK, R. (1974): Anarchy, state, and utopia, Oxford, Blackwell, 1990.

PAINE, T. (1795): Agrarian justice..., http://199.173.224.3/history/paine4.html (1997), según la edición de Filadelfia, B. J. Bache, 1795.

Pareto, W. (1916): Forma y equilibrio sociales (extracto del Tratado de sociología general), Madrid, Alianza, 1980.

Parijs, P. van (1994): «Más allá de la solidaridad. Los fundamentos éticos del Estado del Bienestar y su superación", en R. lo Vuolo (ed.), Contra la exclusión. Las propuestas de ingreso ciudadano, Buenos Aires, Miño y Dávila, 1995.

- (1995): Real freedom for all. What (if anything) can justify capitalism?, Oxford, OUP.

POLANYI, K. (1944): The great transformation. The political and economic origins of our time, Boston, Beacon, 1957, $1 .^{\text {a }}$ ed. rústica.

RAWLS, J. (1971): Teoría de la justicia, Madrid, FCE, 1979.

- (1993): El liberalismo politico, Barcelona, Crítica, 1996.

Ricardo, D. (1817): Principios de Economía Política y Tributación, Madrid, Seminarios y Ediciones, 1973.

SAmuelson, P. A. (1948): Curso de economía moderna, Madrid, Aguilar, 1972.

SChumpeter, J. A. (1912): Teoría del desenvolvimiento económico, México, FCE, $1978^{1+5}$.

- (1942): Capitalism, socialism and democracy, N. York, Harper \& Row, $1950^{3}$.

Smith, A. (1776): The wealth of nations, Harmondsworth, Penguin, $1977^{5}$.

THOMPSON, W. (1825): An inquiry into the principles of the distribution of wealth, Londres, WS Orr, 1850.

Weber, M (1922): Economía y sociedad, México, FCE, 2 vols., 4. ${ }^{\text {a ed., } 1977 .}$

\begin{abstract}
An approach to the problem of inequality, or more specifically that of justice, means starting from a distributive criterion and contrasting the distribution actually existing against this. Locke proposed a theory or standard of the original application referring to the distribution of natural resources, but was unable to solve the problem of intergenerational justice. Marx drew up a value-work theory which was unable to explain why the use of the activity itself as work, rather than its consumption as leisure, would give the right to appropriation of the surplus, but the use of wealth as capital rather than its consumption as income, would not. Rawls suggests the principle of difference as a liberal theory of justice, and in this it is possible to find room for inequalities on the condition that these improve the situation of the worst placed person. This article defends the relevance of all three problems which concern, respectively, the appropriation of natural resources (and, therefore, inherited wealth), the products of labour, and the incentivation of extraordinary contributions. Also proposed, however, is a correction of all three: in the case of the first, replacing the original appropriation with initial endowments to make room for equality between generations; in the second, resorting to a standard of increased work value that includes compensation for abstinence, that is, from capital; in the third, replacing its blind acceptance with idea of starting out from the difference, in other words reducing compensation for extraordinary contributions to the incentive necessary for these.
\end{abstract}

